Family Medicine and Community Health

\title{
Conducting health policy analysis in primary care research: turning clinical ideas into action
}

\author{
Alina Engelman, ${ }^{1}$ Ben Case,${ }^{2}$ Lisa Meeks, ${ }^{2}$ Michael D Fetters ${ }^{3}$
}

To cite: Engelman A, Case B, Meeks L, et al. Conducting health policy analysis in primary care research: turning clinical ideas into action. Fam Med Com Health 2019;7:e000076. doi:10.1136/fmch-2018-000076

Received 01 December 2018 Revised 04 December 2018 Accepted 23 January 2019
Check for updates

(C) Author(s) (or their employer(s)) 2019. Re-use permitted under CC BY-NC. No commercial re-use. See rights and permissions. Published by BMJ.

${ }^{1}$ Health Sciences, California State University, East Bay, Hayward, California, USA

${ }^{2}$ Department of Family Medicine, University of Michigan, Ann Arbor, Michigan, USA

${ }^{3}$ Family Medicine, University of Michigan, Ann Arbor, Michigan, USA

Correspondence to Dr. Alina Engelman; alina.engelman@csueastbay. edu

\section{ABSTRACT}

Healthcare guidelines play a prominent role in the dayto-day practice of primary care providers, and health policy research leads to the formation of these guidelines. Health policy research is the multidisciplinary approach to public policy explaining the interaction between health institutions, special interests and theoretical constructs. In this article, we demonstrate how primary care providers can conduct high-impact health policy research using Eugene Bardach's eightfold policy analysis framework in a primary care context. In a medical case, a woman with a history of total hysterectomy had scheduled a visit for a Papanicolaou (Pap) smear screening test as part of a wellwoman health check-up with a family medicine resident. Conflicting recommendations on Pap smear screening after total hysterectomy sparked an investigation using the US Preventive Services Task Force criteria for conducting a health policy analysis. We illustrate broadly how clinical care dilemmas can be examined by using Bardach's broadly applicable health policy framework in order to inform meaningful policy change. Bardach's framework includes (1) defining the problem, (2) assembling evidence, (3) constructing alternatives, (4) selecting criteria, (5) projecting outcomes, (6) confronting trade-offs, (7) decision-making and (8) sharing the results of the process. The policy analysis demonstrated insufficient evidence to recommend Pap test screening after hysterectomy and the findings contributed to national recommendations. By following Bardach's steps, primary care researchers have a feasible and powerful tool for conducting meaningful health policy research and analysis that can influence clinical practice.

\section{STATEMENT OF SIGNIFICANCE}

Primary care providers often serve at the front lines where patient care and policy intersect and are uniquely situated to conduct health policy research, illustrated by the example of a clinical encounter that prompted clinical policy analysis of the utility of Papanicolaou (Pap) smear screening after total hysterectomy. Bardach's ${ }^{1}$ policy framework can empower primary care providers to engage in health policy research while meeting competing demands of patient care and advocacy, even with limited resources and in the absence of extensive training and research experience.

\section{INTRODUCTION}

Health policy often dictates clinical care protocols and helps physicians and other providers make evidence-based decisions about patient care. However, if recommended actions are conflicting, clinically ineffective, cost-prohibitive or result in questionable health improvements, they warrant review. ${ }^{2}$ Primary care providers are at the intersection of policy and practice and are naturally positioned to address gaps in healthcare policy and to conduct health policy research. Health policy guides many decisions that clinicians make about patient care in preventive, acute, chronic and end-of-life care. Well-crafted health policy has implications for ensuring timely and accurate guidance for healthcare providers to deliver effective medical care. Primary care providers seeking guidance on screening or intervention for patients may find recommendations that do not comport with their daily clinical experiences. This can prompt them to reassess prevailing policy in specific contexts or with unique populations. As health policies profoundly impact patient care and the overall health of populations, health policy analysis is a critical research tool for primary care providers.

Primary care providers operate as the point of first contact where policy intersects with clinical care, and are positioned optimally for recognising gaps, inconsistencies, or questionable guidelines or health policies (table 1). For this reason, primary care physicians should feel empowered to conduct basic policy analysis, regardless of available resources. Our aim for this article is twofold: (1) to introduce the basics of health policy research explicated in Eugene Bardach's eightfold policy analysis framework ${ }^{1}$ and (2) to illustrate the feasibility of conducting health policy analysis by deconstructing the process step by step. Specifically, we use the example of a clinical encounter that prompted clinical policy analysis of the utility of Papanicolaou (Pap) 
Table 1 Health policy analysis studies that have been led by primary care and public health researchers

\begin{tabular}{ll} 
Topic & Recommendation \\
\hline $\begin{array}{l}\text { Utility of Papanicoloau (Pap) screening } \\
\text { after total hysterectomy for benign } \\
\text { disease. }\end{array}$ & $\begin{array}{l}\text { There is insufficient evidence to recommend Pap screening after Fetters, et al }{ }^{14} \\
\text { total hysterectomy for benign disease. }\end{array}$ \\
$\begin{array}{l}\text { Cost-effectiveness of Pap smear } \\
\text { screening for vaginal cancer after total } \\
\text { hysterectomy for benign disease. }\end{array}$ & $\begin{array}{l}\text { As significant costs were associated with any screening strategy Fetters, et al }{ }^{18} \\
\text { without demonstrable gain in life expectancy, the authors } \\
\text { concluded Pap smear screening after total hysterectomy for } \\
\text { benign disease was not cost-effective. }\end{array}$ \\
$\begin{array}{ll}\text { US medical school compliance with the } \\
\text { Americans with Disabilities Act (ADA). }\end{array}$ & $\begin{array}{l}\text { Most U.S. medical school technical standards do not support } \\
\text { provision of reasonable accommodations for students with } \\
\text { disabilities as intended by the Americans with Disabilities Act } \\
\text { (ADA). }\end{array}$ \\
$\begin{array}{l}\text { Support for medical professionals with } \\
\text { disabilities. }\end{array}$ & $\begin{array}{l}\text { A lack of uniform practice contributes to disparate access to } \\
\text { medical education for learners with disabilities. }\end{array}$ \\
\hline
\end{tabular}

smear screening after total hysterectomy that ultimately contributed to policy change. While hospital processes or population-based research studies can inform clinical decision-making, doctors facing individual patients often face additional considerations.

\section{HEALTH POLICY CONTEXT}

Health policy is a course of action and inaction that affects the institutions, organisations, services, clinical practices and funding arrangements of the health system, and generally falls into two categories: (1) policies that define the functions and powers of agencies, or (2) policies aimed at the protection and promotion of health. ${ }^{34}$ While government plays a key role in forming policies, private entities, such as insurance companies, as well as primary care physicians and other influential actors, also contribute to new and revised health policies. ${ }^{4}$

\section{HEALTH POLICY ANALYSIS}

A crucial aspect of health policy formation and change is health policy analysis, a multidisciplinary approach to public policy that aims to explain the interaction among institutions, interests and ideas in the policy process. Often situated as a review of documents and guidelines, health policy analysis is a critical mechanism for ensuring best practices in light of new evidence and the promotion of good health. ${ }^{6}$ For example, the growing evidence of disability-related health disparities, including lung cancer screening among the deaf, and case studies on the inclusion of medical residents with disabilities, can drive policy change. $^{78}$ The Alliance for Disability in Health Care Education, based on existing policy and research literature, crafted a policy document on core competencies on disabilities for healthcare education. ${ }^{9}$ Primary care providers may be called on to create clinical policies within their own practices or within their institution, ${ }^{10}$ to provide national guidance or highlight the lack of policies or need for guidance. ${ }^{9-13}$ Although there is a robust research literature making the case for the importance of policy analysis, there is less guidance on how a practitioner may do so. This overview of health policy analysis procedures is aimed at empowering primary care providers and researchers to identify, improve and prioritise policies that can enhance health policies.

\section{EXAMPLE OF HEALTH POLICY ANALYSIS METHODOLOGY: A STUDY TRIGGERED BY A CLINICAL ENCOUNTER}

We introduce the example of a clinical encounter that prompted a clinical policy analysis of the utility of Pap smear screening after total hysterectomy and ultimately contributed to policy change. Primary care providers are often the primary professional contact for women seeking cancer screening for breast, cervical or colon cancer, placing primary care providers in a unique position to address policies related to women's health. A doctor encountered a woman in her 50s who had scheduled a well-woman health examination including a Pap smear in a family medicine clinic. Chart review indicated she had undergone a total hysterectomy for fibroids, a benign disease. After consulting with the preceptor and reading available guidelines, recommendations about cytological testing after hysterectomy were ambiguous. This prompted a health policy analysis on the utility of Pap smears after total hysterectomy for benign disease (figure 1). ${ }^{14}$

The authors began their health policy analysis by examining (1) the recommendations and quality of guidance provided by multiple organisations vested in women's healthcare and women's cancers; (2) the existing literature on posthysterectomy Pap smear; and (3) recommendations in associated medical textbooks. They examined the risk of malignancy after total hysterectomy for benign disease and the extent Pap test screening after total hysterectomy for benign disease met the three US Preventive Services Task Force (USPSTF) criteria for an effective test. ${ }^{15}$ These criteria include (1) the burden of suffering (does the test accurately identify the disease through screening and do those identified early have better 


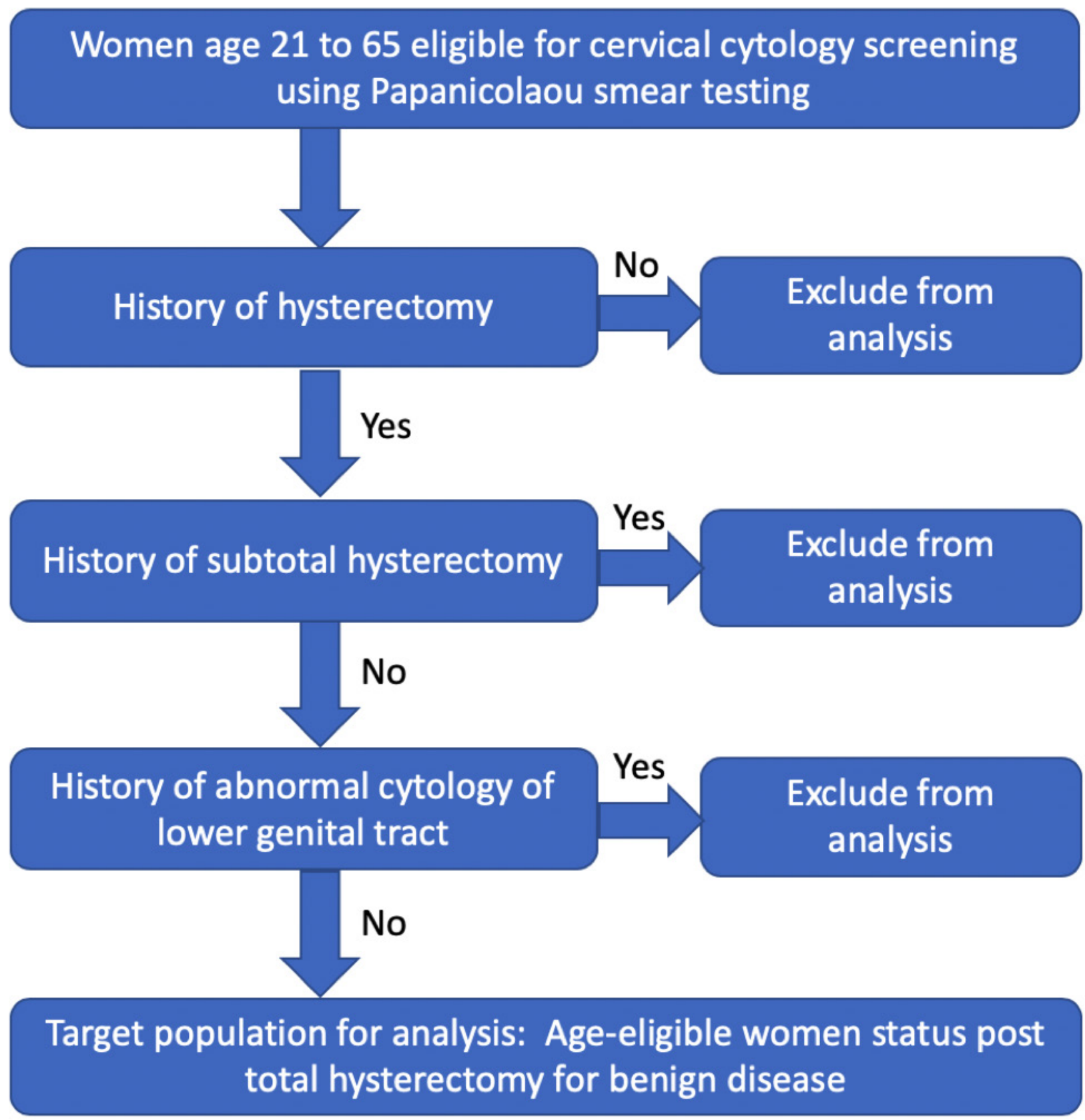

Figure 1 Figure defining a healthcare policy problem prompted by the question of whether women who have undergone hysterectomy should undergo Papanicolaou screening for cancer.

health outcomes?), (2) the accuracy of the screening tool and (3) the effectiveness of early detection. ${ }^{15}$ Having illustrated how the authors used health policy analysis according to the USPSTF criteria, in the following we introduce a broad, widely applicable health policy framework by Bardach. ${ }^{1}$ Bardach's framework affords primary care researchers a comprehensive, step-by-step approach for conducting policy analysis. ${ }^{1}$
STEPS FOR CONDUCTING HEALTH POLICY ANALYSIS: BARDACH'S EIGHTFOLD POLICY ANALYSIS FRAMEWORK

Eugene Bardach ${ }^{1}$ established an eightfold policy analysis framework that is commonly applied in policy and administration research as well as in public health. Bardach's eightfold policy analysis framework includes (1) defining the problem, (2) assembling evidence, (3) constructing alternatives, (4) selecting criteria, (5) projecting outcomes, (6) confronting trade-offs, (7) decision-making and (8) sharing the results of the process. In table 2, we break down Bardach's eightfold policy analysis framework using the same example to illustrate how Bardach's more comprehensive approach can similarly 
Table 2 Example of health policy analysis to inform improvements in guidelines for Pap smears after total hysterectomy for benign disease through Bardach's steps 1-8

\begin{tabular}{ll}
\hline Step & Example from Fetters et al ${ }^{14}$ \\
\hline 1. Define the problem. & $\begin{array}{l}\text { Lack of evidence and controversial recommendations regarding Pap smear screening after total } \\
\text { hysterectomy for benign disease. }\end{array}$ \\
2. Assemble evidence. & $\begin{array}{l}\text { 1. Medline review of medical literature, including case studies, using terms: hysterectomy and vaginal } \\
\text { smears or vaginal smears and vaginal neoplasm. }\end{array}$ \\
& $\begin{array}{l}\text { 2. Review major textbooks of gynaecology. } \\
\text { 3. Review recommendations from major organisations with known background in screening, cancer } \\
\text { and women's health issues. }\end{array}$ \\
3. Construct & $\begin{array}{l}\text { Describe assumptions and positions justifying each policy under consideration, including existing } \\
\text { cervical cancer guidelines of Pap smears after total hysterectomy for benign disease or cessation of } \\
\text { alternatives. }\end{array}$ \\
the practice.
\end{tabular}

8. Sharing the results of Presentation to USPSTF for consideration and subsequent revision of the USPSTF guidelines. the process.

Pap smear, Papanicolaou smear; USPSTF, US Preventive Services Task Force.

illustrate the utility of Pap smears after total hysterectomy for benign disease. ${ }^{14}$

\section{Step 1. Define the problem}

First, in health policy analysis, primary care researchers must define the problem. Defining the problem is critical in policy analysis because it guides the research method and helps establish the structure used in communicating the results. In the exemplar article regarding the utility of Pap smears after total hysterectomy, the authors identify the problem as both a concern that applies to individual patients and as a public problem-one that affects multiple patients, increases healthcare costs, and includes the potential misappropriation of resources without evidence of need or efficacy. ${ }^{14}$ The policy scope was narrowed by excluding a history of abnormal Pap testing and of subtotal hysterectomy where the cervix remains intact. Once the background is synthesised, a problem statement can be developed that will allow for improved public health policies. Given the critical importance of developing the problem statement, this message can consider primary care practice and the need for governmental interventions, as well as relevant public and private collaborations.

\section{Step 2. Assemble the evidence}

Step 2 involves assembling the evidence by investigating the background, trends, and systematic, institutional, interpersonal or financial barriers and facilitators to successful resolution. The research design and scope of the study will dictate the approach to analysis. In the exemplar study, the authors collected and reviewed existing guidance on Pap smear screening after a total hysterectomy, as well as data from from multiple organisations, the medical literature and textbooks. ${ }^{14}$ In reviewing evidence, researchers should explicitly examine their own assumptions and propositions to facilitate a logical process as they compile evidence. Examining assumptions and evidence bases of existing guidelines can often be very informative as well. Once the background is synthesised, the problem statement can be revisited and sharpened to allow for well-defined focus of the policy analysis. As part of defining the problem or assembling evidence, primary care researchers can map a framework through a schematic figure (figure 1). This process permits a comprehensive understanding of the problem to investigate and allows for a more focused literature review on policies, best practices and key barriers as the policy focus evolves.

\section{Step 3. Construct policy alternatives}

Step 3 of Bardach's framework, constructing policy alternatives, guides primary care researchers to consider the advantages and disadvantages of each policy alternative and consider using alternative approaches to policy alone or in combination with other alternatives. Step 3, an explicit description of the assumptions and positions being made for each policy alternative, is critical for successful implementation of the policy. For example, if physicians address a decision choice that requires outside 
funding, they would be explicit in including funding agencies as part of the consideration of its implementation. Additionally, this discussion will aid the understanding of the evolution of policy and evaluation of the success of policy implementation. In the exemplar case, alternatives would include following existing cervical cancer screening guidelines (despite patients no longer having a cervix), an alternative interval or cessation of the practice.

The challenge to primary care researchers in this step is to adequately consider all the plausible alternative solutions and then pare down alternatives that best meet the needs of the population. This means the physician researcher needs to construct alternatives that are responsive to the highly complex environments in which they are made. To strengthen a policy analysis, physicians should also discuss their own assumptions about where they place the efficacy of the alternatives being constructed and consider the policy implementation.

\section{Step 4. Select the criteria}

Selecting the criteria, step 4 in Bardach's framework, explores how alternatives can be measured and evaluated. This is an essential step to determine the effectiveness of current policy. Criteria can be established based on prior research and can include the feasibility of each alternative given local, epidemiological, political and socioeconomic conditions. Considerations can also include primary health outcomes, cost-effectiveness, feasibility of implementation, acceptability, political feasibility, sustainability and practicality.

Selecting the criteria includes establishing how the physician evaluates each alternative and prioritising each option. In determining how the alternatives are evaluated, physicians can draw from their unique perspectives and backgrounds. This includes considering prior research as well as clinical experiences with patients. These experiences, in turn, can inform considerations of the feasibility of each alternative, in addition to local, epidemiological, political and socioeconomic conditions. In the exemplar, the authors used the widely accepted USPSTF criteria to frame the evaluation. ${ }^{14}$

In evaluating the alternatives, physicians can include any clinical or research knowledge on the cost-effectiveness of the alternative. They may establish a scoring system, with low to high, or less favourable to more favourable rankings. This may include categories about the impact on health, the feasibility, and the economic and budgetary impact of the alternative. ${ }^{14}$ It is also important to think about the political implications, particularly if the alternative includes legislative or governmental action. In healthcare, this may involve recommendations or policies of disease specialists. Specialty organisation guidelines can be swayed by potential conflicts of interest based on the outcomes of the policy analysis. For example, policy favouring prostate-specific antigen screening for prostate cancer impacts the revenue of urologists. Policy guiding the frequency of mammograms for breast cancer screening impacts the revenue of radiologists. In the exemplar, multiple professional organisation perspectives were considered. When conducting the analysis, two organisations supported screening, two opposed screening and six lacked specific guidelines. ${ }^{14}$ Physicians should incorporate considerations of the sustainability and practicality of the alternatives, drawing upon their experience-based expertise.

\section{Step 5. Projecting the outcomes}

Often considered the most challenging step, projecting the outcomes is an opportunity to consider how realistic or viable each alternative policy outcome is given resource constraints. In order to project the outcomes, primary care researchers must consider both the direction and the magnitude of the outcome. In the case of Pap smears after a total hysterectomy, it is important to state the positive or negative impact, and to quantify the magnitude of the impact using a point estimate or range. The physician should consider, estimate, project or provide a range for how many cases of cervical cancer are expected to be diagnosed in time for effective treatment as a result of each alternative policy. In the exemplar, the authors weigh the very low incidence of the disease, as well as the costs of false positives inherent in an extremely low prevalence condition. In a situation in which there are resource constraints, it is important to ensure proper balance between unrealistic expectations and cost considerations in light of projected effectiveness. The physician should consider whether simpler or less costly changes in policies and procedures can produce the same or better outcomes. In all projections, the costs of implementing a failed policy and which population would bear those costs need to be measured.

\section{Step 6. Confronting trade-offs}

In step 6, confronting trade-offs, the primary care researcher needs to consider the trade-offs between and within each policy alternative. The trade-offs need to be considered in terms of the criteria by which they can be evaluated, and the criteria themselves need to be weighted. In the exemplar, the researchers considered the trade-offs that could occur should women not receive a yearly Pap smear and the evidence or lack thereof for each, including the potential missed opportunity to check the ovaries for ovarian cancer or the potential for decreased breast cancer screening. A policy alternative that challenges an important criterion, such as survival rate, may need to be discarded even if it stacks up very well in regard to a criterion that may be perceived as less important, such as temporary patient discomfort. In essence, primary care researchers must, within and across each alternative, weigh the relative benefit and importance of each criterion, such as the cost savings of eliminating screenings against the relative risks of missed diagnoses. 


\section{Step 7. Decision-making}

Decision-making is an opportunity for primary care researchers to go through the process of clarifying the costs and benefits in order to present a final decision to stakeholders. This will ensure that, when they explain the costs and benefits, their explanations are clear and the logic behind their choice is sound and easy to follow. In the exemplar study, using the criteria of the USPSTF, the authors concluded that there was insufficient evidence to support Pap smear testing after total hysterectomy for benign disease.

\section{Step 8. Sharing the results of the process}

Sharing the results of the process may take the form of a narrative, and primary care researchers need to clearly understand the reasons behind their decision. Most importantly, primary care researchers need to define the audience and 'pitch' the story to a target population, keeping in mind both the larger political environment and the storytelling medium. In the exemplar, the results of the analysis were shared with a member of the USPSTF, and the full paper was sent for consideration as part of the USPSTF cervical cancer screening guidelines. Shortly afterwards, another paper demonstrated very low yield of any abnormalities in vaginal cytological smears obtained after total hysterectomy. ${ }^{16}$ In contrast to the first edition of the USPSTF guidelines, ${ }^{15}$ the second edition of the USPSTF ${ }^{17}$ provided a recommendation against Pap smear screening after total hysterectomy for benign disease. An additional analysis published by the authors demonstrated poor cost-effectiveness of testing, and the USPSTF continues to recommend against Pap test after total hysterectomy for benign disease. ${ }^{18} 19$ When presenting findings and recommendations, the family physician should consider the audience and tailor the 'pitch' accordingly. If hospital administrators are the decision-makers, consider whether an oral presentation or a written policy document is warranted, or whether a combination of the two is best for communicating key points.

Using new media interventions, primary care researchers conducting health policy analysis can share their findings in an impactful way to inform, persuade and motivate their audience. ${ }^{20}$ Media interventions are often used to communicate health research to other health professionals, patients and policy makers through social media, including Twitter. Abstracts shared via Twitter infograph can elicit interest in a full report or manuscript and has the potential to effectively share health-related research to policy makers and the public. ${ }^{21}$ Depending on the specific topic, writing an op-ed or commentary for local or national professional journals, organisations or newspapers can help to stimulate public interest in the topic and catch the attention of policy makers. Rather than using one media strategy, primary care researchers doing health policy analysis should consider multiple strategies and messages tailored to specific target audiences. Strategies may shift depending on the audience, which can include the public, healthcare providers, grant funding agencies and policy makers.

\section{DISCUSSION}

Conducting a health policy analysis has the potential to change clinical practice at the national and international levels. While the initial step of defining the problem is critical, the lack of guidelines or conflicting guidelines among various organisations remains both a challenge and an invitation to conduct all steps of Bardach's policy analysis. Yet the process requires a primary care researcher to spend considerable time engaging in all steps, including a review of the academic literature. Reviewing current health policies requires access to the literature and the analytical skills needed to interpret the evidence. After identifying a valid health policy problem, a physician should consider seeking assistance from an established health policy analyst or health economist with previous experience in the topic at hand.

An information sciences specialist could greatly enhance a policy analysis by grounding data in a rich evidence base, if available through academic affiliates. Policy analysis requires a critical eye for identifying guidelines that are not well supported by empirical evidence. For some clinical issues, there may be insufficient information to support changes in practice, even though a provider has identified an important policy question. Fortunately, the Bardach framework provides an approach to this limitation. Primary care researchers with limited infrastructure may need to think creatively about how to disseminate findings and analysis beyond publication in the academic literature, including the use of new media.

\section{ADDITIONAL RESOURCES}

In addition to Bardach's framework, readers may find helpful sources and approaches for policy analysis. ${ }^{1}$ The Centers for Disease Control and Prevention policy analytical framework may be helpful prior to policy implementation. $^{22}$ Bodenheimer and Grumbach ${ }^{23}$ are family physicians and policy analysts who provide a clinical perspective on policy analysis. Teitelbaum and Wilensky ${ }^{4}$ offer a perspective on the intersection of health policy and law, including an overview of case law and the ethics of health policy. Dunn ${ }^{24}$ provides a resource with a public policy analysis focus.

\section{CONCLUSIONS}

Primary care providers are often at the front lines where patient care and policy intersect and are uniquely situated to conduct health policy research. The scale of health policy analysis by primary care providers can range from setting clinical policies within their own practices, institutions and organisations, or 
on a nationwide scale. As illustrated by the featured policy analysis of Pap testing after total hysterectomy for benign disease, meaningful policy research can arise from a single clinical experience for a researchminded family physician. As some health policies and guidelines do not pose a financial conflict of interest, policy framing by primary care providers may provide invaluable balance with regard to recommendations for or against services. Primary care researchers need to recognise that they have a unique power to drive policy change. Due to primary care providers' front-line expertise, their concerns are widely viewed as practical, can motivate policy research and help attract funding. Bardach's policy framework can empower primary care providers to engage in health policy research while meeting competing demands of patient care and advocacy, even in the absence of extensive training and research experience.

Contributors $A E$ developed the conceptual framework, wrote and revised the manuscript. BC contributed to revisions, including references and formatting. LM contributed to manuscript writing and analysis. MDF contributed to manuscript edits.

Funding The authors have not declared a specific grant for this research from any funding agency in the public, commercial or not-for-profit sectors.

Competing interests None declared.

Patient consent for publication Not required.

Provenance and peer review Not commissioned; internally peer reviewed.

Open access This is an open access article distributed in accordance with the Creative Commons Attribution Non Commercial (CC BY-NC 4.0) license, which permits others to distribute, remix, adapt, build upon this work non-commercially, and license their derivative works on different terms, provided the original work is properly cited, appropriate credit is given, any changes made indicated, and the use is non-commercial. See: http://creativecommons.org/licenses/by-nc/4.0

\section{REFERENCES}

1. Bardach E. A practical guide for policy analysis: the eightfold path to more effective problem solving. New York: Chatham House Publishers, Seven Bridges Press, 2000.

2. Clancy CM, Glied SA, Lurie N. From research to health policy impact. Health Serv Res 2012;47:337-43.

3. Ghaffar A, Gilson L, Tomson G, et al. Where is the policy in health policy and systems research agenda? Bull World Health Organ 2016;94:306-8.
4. Teitelbaum JB, Wilensky SE. Essentials of health policy and law. Sudbury, Mass.: Jones \& Bartlett Learning, 2013.

5. Walt G, Shiffman J, Schneider H, et al. 'Doing' health policy analysis: methodological and conceptual reflections and challenges. Health Policy Plan 2008;23:308-17.

6. Sheikh K, Gilson L, Agyepong IA, et al. Building the field of health policy and systems research: framing the questions. PLoS Med 2011;8:e1001073.

7. Kushalnagar P, Engelman A, Sadler G. Deaf patient-provider communication and lung cancer screening: health information national trends survey in American sign language (HINTS-ASL). Patient Educ Couns 2018;101:1232-9.

8. Meeks LM, Engelman A, Booth A, et al. Deaf and Hard-of-Hearing learners in emergency medicine. West J Emerg Med 2018;19.

9. Alliance for Disability in Health Care Education. Core competencies on disabilities for health care education. Peapack, NJ: Alliance for Disability in Health Care Education, 2017.

10. University of Michigan. Clinical care guidelines. Ann Arbor, Michigan: Michigan Medicine, 2017.

11. Meeks LM, Jain NR. Accessibility, inclusion, and action in medical education: lived experiences of learners and physicians with disabilities. Washington, DC: Association of American Medical Colleges, 2018.

12. Viglianti EM, Oliverio AL, Meeks LM. Sexual harassment and abuse: when the patient is the perpetrator. Lancet 2018;392:368-70.

13. Zazove P, Case B, Moreland C, et al. U.S. medical schools' compliance with the Americans with Disabilities Act: findings from a national study. Acad Med $2016 ; ; 91: 979-86$. July 01.

14. Fetters MD, Fischer G, Reed BD. Effectiveness of vaginal Papanicolaou smear screening after total hysterectomy for benign disease. JAMA 1996;275:940-7.

15. U.S. Preventive Services Task Force. Guide to clinical Preventive Services report of the U.S. Preventive Services Task Force. Rockville, MD: Agency for Healthcare Research and Quality, 1989.

16. Pearce KF, Haefner HK, Sarwar SF, et al. Cytopathological findings on vaginal Papanicolaou smears after hysterectomy for benign gynecologic disease. N Engl J Med 1996;335:1559-62.

17. Houston TP, Elster AB, Davis RM, et al. The U.S. Preventive Services Task Force guide to clinical Preventive services, second edition. AMA Council on scientific Affairs. Am J Prev Med 1998;14:374-6.

18. Fetters MD, Lieberman RW, Abrahamse PH, et al. Cost-effectiveness of Pap smear screening for vaginal cancer after total hysterectomy for benign disease. J Low Genit Tract Dis 2003;7:194-202.

19. Bibbins-Domingo K, Grossman DC, Curry SJ, et al. Screening for gynecologic conditions with pelvic examination: US Preventive Services Task Force recommendation statement. JAMA 2017;317:947-53.

20. Wakefield MA, Loken B, Hornik RC. Use of mass media campaigns to change health behaviour. Lancet 2010;376:1261-71.

21. Kapp JM, Hensel B, Schnoring KT. Is Twitter a forum for disseminating research to health policy makers? Ann Epidemiol 2015;25:883-7.

22. Centers for Disease Control and Prevention. CDC's Policy Analytical Framework. Atlanta, GA: Centers for Disease Control and Prevention, US Department of Health and Human Services, 2013.

23. Bodenheimer T, Grumbach K. Understanding health policy. McGraw Hill professional, 2012.

24. Dunn WN. Public policy analysis: an introduction. 5th edn. Boston: Pearson, 2012. 